Mongolian Academy of Sciences
Mongolian Journal of Chemistry
Institute of Chemistry \& Chemical Technology

\title{
Study on arsenic removal process from water
}

\author{
B.Bayarmaa ${ }^{1}$, E.Selenge ${ }^{1}$, Yang Min $^{2}$ \\ ${ }^{1}$ Health Science University of Mongolia. \\ ${ }^{2}$ Research Center for Eco-Environmental Sciences, CAS. \\ chuluun73@yahoo.com
}

\begin{abstract}
In this study a novel adsorbent, iron oxide, is used for As (V) or As (III) removal. Some ferric oxides have been reported to be effective for arsenic removal. Ferric oxides powder is a good adsorbent material since it's has magnetic properties and a good adsorption capacity. The main purpose of this study has been focused on to study the relationship between adsorption capacity (ability, performance) and the surface characteristics of the ferric oxide. Prepared sample's capacity was evaluated. The value was 26.1-67.4 mg/g for As (V) and 20.5-47.8 mg/g for As (III). $\mathrm{pH}$ dependence was evaluated and when $\mathrm{pH}$ increasing, adsorption capacity was decreased. The kinetic was evaluated and about 12 hours reached equilibrium and a capacity of $49 \mathrm{mg} / \mathrm{g}$ for As (V) and 42 $\mathrm{mg} / \mathrm{g}$ for As(III) was gained. The kinetic constants for arsenic adsorption on the ferrihydrite adsorbent's were fitted.
\end{abstract}

Keywords. Ferrihydrite, adsorption, arsenic removal

\section{Introduction}

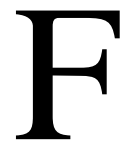
Terrihydrite is an iron oxy-hydroxide known to play an important role in the natural environment and fresher it is, higher the adsorption capacity it has. Its large surface area, strong adsorptive properties, and low cost make it an attractive material for removal of both cationic and anionic impurities from wastewater and drinking water. The use of ferrihydrite to remove arsenic from hydrometallurgical process solutions and wastewaters has received a great deal of attention over a number of years. Ferrihydrite readily adsorbs arsenic (V) in the form of arsenate anion $\left(\mathrm{AsO}_{4}{ }^{3-}\right)$, but probably the most effective method of removal of arsenic from aqueous solutions is through coprecipitation of arsenic with ferrihydrite.(1) The main arsenic removal techniques from drinking water are: oxidation, precipitation/co precipitation, coagulation, sorption, ion- exchange and reverse osmosis. Although these methods have been widely employed, they have several drawbacks: high operating and waste treatment costs, high consumption of reagents and large volume of sludge formation. In contrast, adsorption methods are considered to be very important because of their treatment stability, easy operation and compact facility. When the loaded adsorbent can be regenerated properly, the process can be sludge free. Conventional adsorbents used in arsenic removal are activated carbons and alumina, soils and resins which can be coated with different materials like iron or alumina. (The major disadvantages of these techniques are difficult separation (centrifugation or filtering), waste formation (both liquid and sludge) and in many cases poor adsorption capacity.) So in this study I use ferric oxides. 


\section{Experimental.}

Materials. All the chemicals used were of analytical reagent grade. A $100 \mathrm{mg} / 1 \mathrm{As}$ (V) and As (III) stock solutions were prepared by dissolving $\mathrm{Na}_{3} \mathrm{AsO}_{4} \cdot 12 \mathrm{H}_{2} \mathrm{O}$ or $\mathrm{As}_{2} \mathrm{O}_{3}$ in 1 liter of distilled water. As(V) or As(III) bearing water were prepared by diluting $\operatorname{As}(\mathrm{V})$ or As(III) stock solutions to given As concentrations.

Preparation. The iron based adsorbent was prepared by mixing $\mathrm{Fe}\left(\mathrm{NO}_{3}\right)_{3} \cdot 9 \mathrm{H}_{2} \mathrm{O}$ and $\mathrm{KOH}$ for 20 minutes at $\mathrm{pH} 9.5$. In all the process, the mixed solution needs to be intensely stirred. Then the pulp was settled, and supernatant was discarded. And the paste was washed with distilled water for many times until the conductivity lower than 500 $\mu \mathrm{s} / \mathrm{cm}^{2}$. Then the paste was oven drying at 45 ${ }^{\circ} \mathrm{C}$ to make it dry about $48-72$ hours. Also the drying process can be substituted or refrigerated centrifugation. After that prepared samples were powdered by agate mortar.

Isotherm experiments were carried out in 250 $\mathrm{ml}$ conical flasks, with a reaction volume of $100 \mathrm{ml}$, and the initial As(V)/As(III) concentration:

$8,10,12,18,24,26,30,34,38$ $\mathrm{mg} / \mathrm{l}$. The adsorbent was fixed at a dose of $300 \mathrm{mg} / \mathrm{l}$. The $\mathrm{pH}$ of the suspension was adjusted and kept at $\mathrm{pH} 5.0 \pm 0.1$ during the experiment period. These flasks were shaken at $160 \mathrm{rpm}$ and maintained at $25 \pm 1{ }^{\circ} \mathrm{C}$ for 24 hours. And the solutions were filtered with a $0.45 \mu \mathrm{m}$ cellulose acetate membrane, then the concentrations of the residual As was analyzed in using HG-AFS.

To investigate the influence of $\mathrm{pH}$ on the As adsorption, experiments were carried out in $250 \mathrm{ml}$ vessels, containing $25 \mathrm{mg} / \mathrm{l} \mathrm{As}(\mathrm{V})$, respectively, with $300 \mathrm{mg} / \mathrm{l}$ adsorbent and a total suspension volume of $100 \mathrm{ml}$. And the equilibrium $\mathrm{pH}$ was adjusted in the range of 3 to 10 at an experiment period of 24 hours. During the experiment, samples were shaken at $160 \mathrm{rpm}$, and the temperature was controlled at $25 \pm 1{ }^{\circ} \mathrm{C}$. After reaction, the final $\mathrm{pH}$ values were recorded, and the solutions were filtered with a $0.45 \mu \mathrm{m}$ cellulose acetate membrane, and the concentrations of the residual As were analyzed.

In order to evaluate the adsorption rate, the kinetics experiments were performed at room temperature $\left(21-25{ }^{\circ} \mathrm{C}\right)$. Some amounts stock solution was added in $2000 \mathrm{ml}$ to make a total volume of $1500 \mathrm{ml}$, with initial As concentrations of $25 \mathrm{mg} / \mathrm{l}$. Then, $0.45 \mathrm{~g}$ of ferrichydrite was added to obtain a $300 \mathrm{mg} / \mathrm{l}$ suspension. Further the $\mathrm{pH}$ of the mixed suspended solution was adjusted and maintained at $5.0 \pm 0.1$ throughout the experiment by addition $0.05 \mathrm{M} \mathrm{HCl}$ or $\mathrm{NaOH}$. The suspension was mixed with a magnetic stirrer at an agitation speed of about $160 \mathrm{rpm}$. Approximately $5 \mathrm{ml}$ aliquots were taken from the suspension at $0,30 \mathrm{~min}, 1 \mathrm{~h}, 4 \mathrm{~h}, 8 \mathrm{~h}, 12$ $\mathrm{h}, 24 \mathrm{~h}, 30$ hours. The samples were immediately filtered through a $0.45 \mu \mathrm{m}$ cellulose acetate membrane. The concentrations of residual As were analyzed by HG-AFS.

\section{Results and Discussion}

Prepared Ferrihydrite's sample. Prepared adsorbent's adsorption capacity was presented Figure 1.

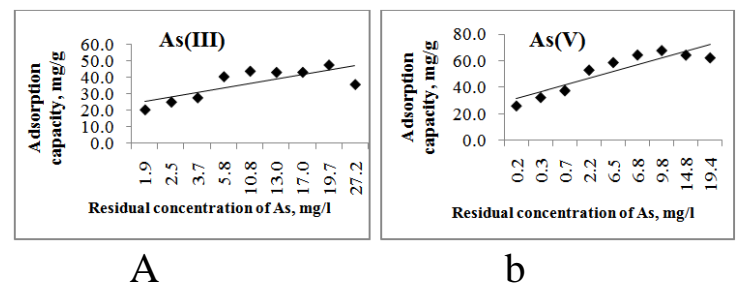

Figure 1. Adsorption isotherm.
a. As(III);
b. $\operatorname{As}(\mathrm{V})$.

The value was $26.1-67.4 \mathrm{mg} / \mathrm{g}$ for As(V)and 20.5-47.8mg/g for As(III).

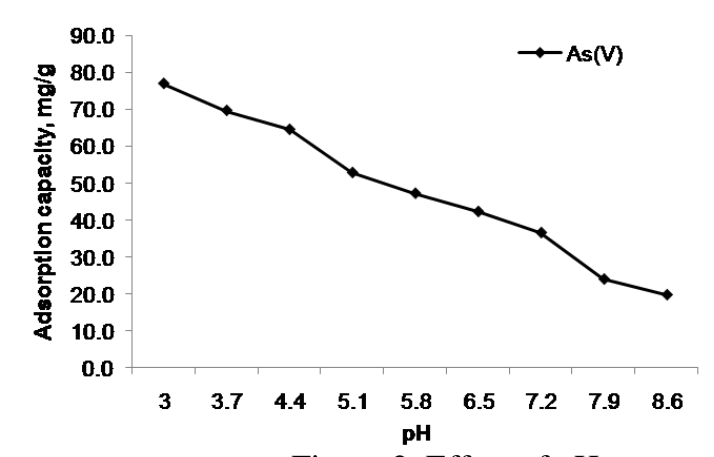

Figure 2. Effect of $\mathrm{pH}$. 
$p H$ dependence was presented Figure 2 and when $\mathrm{pH}$ increasing adsorption capacity was decreasing.

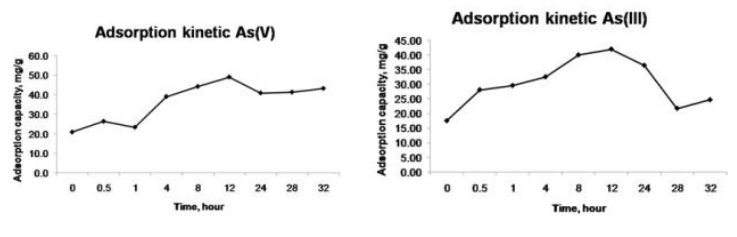

A b

Figure 3. Adsorption kinetics.
a. $\operatorname{As}(\mathrm{V})$;
b. As(III).

The kinetic results are presented Figure 3 and about 12 hours reached equilibrium and a capacity of $49 \mathrm{mg} / \mathrm{g}$ for $\mathrm{As}(\mathrm{V})$ and $42 \mathrm{mg} / \mathrm{g}$ for As(III) was gained.

The kinetic constants for arsenic adsorption on the ferrihydrite adsorbant's were fitted and showed following Table 1.

\begin{tabular}{|c|c|c|c|c|c|c|}
\hline $\begin{array}{c}\text { Initial } \\
\text { concent } \\
\text { rations, } \\
25 \mathrm{mg} / \mathrm{l}\end{array}$ & \multicolumn{2}{|c|}{ Pseudo-first-order model } & \multicolumn{3}{|c|}{ Pseudo-second-order model } \\
\cline { 2 - 7 } & $\begin{array}{c}\mathrm{K}_{1}, \\
\mathrm{~min}\end{array}$ & $\begin{array}{c}\mathrm{q}_{\mathrm{e}}, \\
\mathrm{mg} / \mathrm{g}\end{array}$ & $\mathrm{R}^{2}$ & $\mathrm{~K}_{2}, 1 / \mathrm{min}$ & $\begin{array}{c}\mathrm{q}_{\mathrm{e}}, \\
\mathrm{mg} / \mathrm{g}\end{array}$ & $\mathrm{R}^{2}$ \\
\hline $\mathrm{As}(\mathrm{V})$ & 0.039 & 21.58 & 0.803 & 0.0041 & 43.48 & 0.995 \\
\hline $\mathrm{As}(\mathrm{III})$ & & & & -0.00047 & 25 & 0.933 \\
\hline
\end{tabular}

Table 1. Kinetic constants for arsenic adsorption on the ferrihydrite adsorbent.As shown in the table, the result of the study is approved accurately.

\section{Conclusion}

An iron based inorganic adsorbent was used for both $\mathrm{As}(\mathrm{V})$ and $\mathrm{As}(\mathrm{III})$ removal. In terms of adsorption $\mathrm{pH}$ range and adsorption capacity, the new adsorbent demonstrated the probable result. The adsorption mechanism, however, requires further studies.

\section{Acknowledgement}

We would like to express our sincere gratitude to Professor Min Yang, and for his important support throughout this work.

\section{References.}

1. William R. Richmond, Mitch Loan, Jonathan Morton and Gordon M. Parkinson. (2004) Environ.Sci.Techno. 38, 2368-2372

2. Yu Zhang, Min Yang, Xia Huang. (2003) Chemosphere. 51, 945-952.

3. V.J. Inglezakis, Helen Grigoropoulou.(2004) Journal of Hazardous Materials B112 37-43. Effects of operating conditions on the removal of heavy metals by zeolite in fixed bed reactors

4. H. Takase, N. Katoh. (1995), J. Chem. Eng. Jpn.28 165-170. Recovery of heavy metal ion from slurry adsorbent by packed column of ion exchange.

5. Do, D. D. (1998). London:Imperial College Press. Adsorption analysis: equilibria and kinetics. 